\title{
Current Management of Membranous Urethral Strictures Due to Radiation
}

\begin{abstract}
Marjan Waterloos ${ }^{1,2+}$, Francisco Martins ${ }^{3}$, Wesley Verla ${ }^{2 \dagger}$, Luis Alex Kluth ${ }^{4 *}$ and Nicolaas Lumen ${ }^{2}$ for the Trauma Reconstructive Urology Working Party of the European Association of Young Academic Urologists
\end{abstract}

${ }^{1}$ Department of Urology, AZ Maria Middelares Ghent, Ghent, Belgium, ${ }^{2}$ Department of Urology, University Hospital Ghent, Ghent, Belgium, ${ }^{3}$ Department of Urology, University of Lisbon School of Medicine, Lisbon, Portugal, ${ }^{4}$ Department of Urology, University Hospital Frankfurt, Frankfurt am Main, Germany

\section{OPEN ACCESS}

Edited by:

Marianne Schmid,

University Medical Center

Göttingen, Germany

Reviewed by:

Matthias D. Hofer,

Northwestern Memorial Hospital,

United States

Miroslav Djordjevic,

University of Belgrade, Serbia

*Correspondence:

Luis Alex Kluth

luis.kluth@kgu.de

†Senior members of the Trauma and Reconstructive Urology Working Party of the European Association of Young Academic Urologists

Specialty section This article was submitted to Genitourinary Surgery, a section of the journal

Frontiers in Surgery

Received: 29 November 2020 Accepted: 01 February 2021

Published: 04 March 2021

Citation:

Waterloos M, Martins F, Verla W, Kluth LA and Lumen N (2021) Current

Management of Membranous Urethral Strictures Due to Radiation.

Front. Surg. 8:635060.

doi: 10.3389/fsurg.2021.635060
Radiotherapy is a frequently used treatment for prostate cancer. It does not only causes the intended damage to cancer cells, but also affects healthy surrounding tissue. As a result radiation-induced urethral strictures occur in $2.2 \%$ of prostate cancer patients. Management of urethral strictures is challenging due to the presence of poor vascularized tissue for reconstruction and the proximity of the sphincter, which can impair the functional outcome. This review provides a literature overview of risk factors, diagnostics and management of radiation-induced urethral strictures.

Keywords: urethal stricture, radiotherapy, membranous urethral stricture, radiation-induced, urethroplasty

\section{INTRODUCTION}

Prostate cancer is the second most frequent cancer in men. Treatment options in localized prostate cancer are active surveillance, surgical treatment or radiation therapy (External Beam Radiotherapy EBRT, Brachytherapy BT or combination of both).

Radiation therapy for prostate cancer is the chosen treatment in approximately $25-34 \%(1,2)$.

Radiation causes ionization events and production of free radicals resulting in different types of DNA damage, eventually leading to vascular injury (endarteritis) and stem cell damage. This leads to atrophy and poorly oxygenated tissue with eventual tissue scarring (3). While intended in cancer cells, it also affects healthy tissue, resulting in a range of side-effects and pathology.

Radiation induced urethral strictures usually occur at the bulbomembranous urethra, even though theoretically receiving lower radiation dose (4).

Hughes et al. examined the specimens of patients who underwent a urethroplasty for a membranous stricture and found that post-radiation specimens had a significantly decreased vascularity compared to specimens of non-radiated etiology (5).

The management of radiation induced strictures remains challenging. It differs from non-radiotherapy related strictures by the scarred tissue with reduced healing capacity. Due to the proximity of the sphincter functional outcome may be impaired (6).

Since the high rates of curation or disease control of prostate cancer nowadays, quality of life is very important to consider in the treatment of these strictures (1).

For the purpose of this review we searched the pubmed library from the year 2000 to 2020. 


\section{EPIDEMIOLOGY, ETIOLOGY, AND RISK FACTORS}

The prevalence of radiation induced urethral strictures in prostate cancer patients is $2.2 \%$ at a median follow-up of 4 years: $1.5 \%$ in patients undergoing External Beam Radiotherapy (EBRT), $1.9 \%$ in patients undergoing Brachytherapy (BT) and $4.9 \%$ in patients receiving a combination of both EBRT-BT. When EBRT is used as a salvage treatment stricture incidence increases to $3-10 \%(1,6,7)$.

Stricture incidence will increase with time, in contradiction with strictures after radical prostatectomy $(8,9)$. Median time to stricture formation is estimated between 2.2 and 3.4 years after radiation therapy (1). The CaPSURE database revealed a stricture rate of $1 \%$ directly after treatment to $16 \%$ after 4 years (7).

A systematic review of Awad showed no difference in urethral stricture development concerning age, proportion of patients on Androgen Deprivation Therapy (ADT) and biochemically equivalent dose (BED) (1). This last observation is also found in the ASCENDE-RT trial, where only little correlation between urethral stricture and dose to the prostate was found (10). Other studies (case series, case control series) demonstrated a clear dose-related effect on urinary morbidity (11-13). Hindson et al. reports an increased stricture rate when radiotherapy was separated in 2 sessions, in comparison of 3 and 4 treatments (14).

In brachytherapy the region inferior to the apex is commonly referred to as "the hotspot" (15). Decreasing the radiation dose to the hot spot, special care during BT-needle placement, avoiding midline insertions, and using plastic needles instead of steel needles, have shown to be effective measures to reduce the rate of urethral strictures (1).

Multiple studies demonstrated clearly an increased risk of urethral stricture in patients who had a TURP prior to radiation therapy. Underlying mechanism is thought to be devascularization of the urethra after TURP in combination with mucosal impairment due to radiation damage $(4,16,17)$.

It remains controversial whether combination with hormonal therapy increases the risk of urinary morbidity $(11,18)$. According to the CaPSURE database there was no change in stricture rate therapy when ADT was associated to another treatment (7). This was also the conclusion in the systematic review of Awad (1).

\section{DIAGNOSTICS}

Diagnostic workup is important for planning of the surgical intervention, and can be tailored on a case per case base.

Patients with radiation-induced strictures will present more often with storage lower urinary tract symptoms (LUTS) as a side-effect of their prior radiotherapy treatment. It can be important to determine the pre-operative bladder function by performing a urodynamic study. In other cases uroflowmetry will be sufficient. Radiographic evaluation of the length and location of the stricture is necessary. When a retrograde urethrogram (RUG) is insufficient to evaluate the bladder neck a voiding urethrocystogram (VCUG) can be performed (6).
According to the SIU/ICUD consultation on urethral strictures diagnostic workup for posterior urethral stricture should consist of history, physical examination, laboratory investigations (urine, renal function, prostate-specific antigen), uroflowmetry an postvoid residual volume, cystoscopy and antegrade cystoscopy when evaluation of the anatomy proximal of the stenosis is needed. On indication a retrograde urethrography, voiding cystourethrography, prostate and upper urinary tract imaging or urodynamic evaluation can be performed (2).

\section{TREATMENT}

\section{Conservative}

In case surgical management is not useful or feasible, chronic urinary catheter will allow urinary drainage. A chronic suprapubic catheter can be a viable option in frail or therapy refractory patients with complete urethral obliteration (19).

Incontinence can be a predominant feature even in patients with urethral strictures. Conservative options for incontinence include penile clamp, condom catheter, and use of sanitary pads (20).

In a study of Fuchs urinary diversion is also used as a measure to obtain urethral rest prior to reconstructive surgery. At a follow-up period of 6 months $49 \%$ of the patients preferred to keep their chronic suprapubic tube, instead of undergoing a urethroplasty (21).

All complications related to chronic urinary drainage, such as irritative symptoms, bladder pain, infection and stone formation should be taken in consideration.

\section{Endoluminal}

Even in non-radiation related strictures endoluminal treatment has poor results, especially in longer and high grade strictures. Due to impaired tissue quality the outcome in radiation-induced strictures is even poorer. When there is a complete obliteration of the urethral lumen, endoluminal treatment is contra-indicated.

Brandes et al. reports different results after Direct Vision Internal Urethrotomy (DVIU) or dilatation according to the treatment modality: stricture recurrence time of 3.7, 26, and 10.9 months after BT, EBRT and combination BT-EBRT, respectively. Total success rate at 4 years follow-up is $20 \%$ with EBRT and $0 \%$ with $\mathrm{BT}$, concluding to endoluminal treatment as a palliative option (22). Chen et al. demonstrated a stricture recurrence rate of 50\% within 16-60 months after DVIU or dilatation (23).

Sullivan et al. studied a relatively large cohort of patients treated with brachytherapy, followed by endoluminal treatment and a recurrence rate of $49 \%$ was reported at a median follow-up of 16 months (4).

Merrick reports a higher patency rate of $69 \%$ in a retrospective case series (13).

To stabilize fibrosis after endoluminal treatment intermittent self-dilatation (ISD) can be attempted (6). This should be considered as a palliative treatment, in patients who are unwilling or unable to undergo more invasive surgical strategies $(4,13,24)$. On the other hand some authors state that repetitive endoluminal treatment might induce further fibrosis (25). 
The conclusion of a study of Lubahn about quality of life in patients performing ISD, states that it is inappropriate to implement ISD in patients that are still amenable for reconstruction, since it's associated with a decrease in quality of life (26).

\section{Open Reconstruction Excision and Primary Anastomosis}

This technique will provide a durable long-term outcome, when surrounding scarred tissue is resected and a tension-free anastomosis can be achieved (Table 1).

Rourke published a case series of 35 patients, in which EPA was performed in $65.7 \%$ of the cases, and in the other cases buccal mucosa or penile skin flap was used for substitution urethroplasty. All patients had failed prior endoscopic treatment. Strictures treated with EPA and substitution urethroplasty had a mean length of 2.1 and $6.1 \mathrm{~cm}$, respectively. They were all located at the bulbomembranous urethra. Patency rate after follow-up of 4 years was $91 \%$ for EPA and $75 \%$ for substitution urethroplasty.

One out of four patients complained of worsening or new onset of urinary incontinence, of which $50 \%$ had a prior TURP.

In total $68.6 \%$ of patients reported a change in continence, erectile function or voiding function after treatment, even when an unobstructed urethra was achieved. This last finding is most likely related to radiotherapy-induced bladder dysfunction (27).

Hofer et al. demonstrates a success rate of $70 \%$ with EPA in a group of 66 patients, with mean stricture length of $2.4 \mathrm{~cm}$. De novo postoperative urinary incontinence was reported in $36 \%$ of the cases. Strictures longer than $2 \mathrm{~cm}$ were associated with a greater risk of incontinence.

New onset erectile dysfunction was reported in only $7 \%$ of the patients. Stricture location or length was not associated with erectile function (28).
A subsequent cohort from the same group a few years later showed an improved success rate of $85 \%$, attributed to increased surgeon experience. There was a decreased incontinence rate, however presentation of more severe urinary incontinence. Risk of recurrence was not associated with the length of follow-up, concluding that recurrence occurred in the early postoperative period (31).

In a study of Glass et al. 29 patients were treated with EPA (76\%), buccal graft urethroplasty (17\%) and perineal flap urethroplasty $(7 \%)$ for radiation-induced strictures with a median length of $2.6 \mathrm{~cm}$. An overall success rate of $90 \%$ was reported. Outcome on continence and erectile function was not reported (29).

In another case series of Meeks et al. 30 patients underwent urethroplasty for radiation-induced strictures, all had previous failed endoscopic treatments. Overall patency rate after EPA $(84 \%)$ and substitution urethroplasty (16\%) was $73 \%$. Follow-up was only 21 months. Urinary incontinence after surgery occurred in $50 \%$ of the patients. There was no significant change in erectile function (30).

Elliott et al. reports a success rate of $72 \%$ after urethroplasty for strictures after prostate cancer treatment, however this was a very heterogenous cohort and there was a wide range of stricture etiology and surgical techniques. Again, radiation therapy was suggested as an important predictive factor for stricture recurrence. An algorithm was developed, in which long radiation (EBRT) induced strictures are advised to be treated with perineal urethrostomy instead of other reconstructive techniques (flaps or two staged procedures) (34).

Higher urinary stress incontinence rates are reported when EPA is performed for radiation-induced strictures (33\%), in comparison to pelvic fracture related injuries (12\%) in a small retrospective case series of Chung (35).

TABLE 1 | Urethroplasty for radiation-induced strictures.

\begin{tabular}{|c|c|c|c|c|c|c|c|c|c|c|c|c|c|}
\hline & $\begin{array}{l}\text { Urethroplasty } \\
\text { technique }\end{array}$ & $N$ & $\begin{array}{c}\text { FU } \\
\text { (years) }\end{array}$ & EBRT & BT & $\begin{array}{l}\text { EBRT/ } \\
\text { BT }\end{array}$ & Other & $\begin{array}{l}\text { Time to } \\
\text { stricture } \\
\text { development } \\
\text { (years) }\end{array}$ & $\begin{array}{l}\text { Mean } \\
\text { stricture } \\
\text { length } \\
\text { (cm) }\end{array}$ & $\begin{array}{l}\text { Patency } \\
\text { rate }(\%)\end{array}$ & $\begin{array}{l}\text { Time to } \\
\text { recurrence } \\
\text { (months) }\end{array}$ & $\begin{array}{l}\text { New onset } \\
\text { incontinence } \\
(\%)\end{array}$ & $\begin{array}{c}\text { Deterioration } \\
\text { erectile } \\
\text { function (\%) }\end{array}$ \\
\hline \multirow[t]{2}{*}{ Rourke et al. (27) } & EPA & 23 & 4.25 & 20 & 15 & $N R$ & 0 & 4.9 & 2.1 & 91 & 29.8 & 26 & 35 \\
\hline & Graft/Flap & 12 & & & & & & & 6.1 & 75 & & 25 & 0 \\
\hline Hofer et al. (28) & EPA & 66 & 3.5 & 28 & 28 & 9 & 1 & 6.4 & 2.4 & 70 & 10.15 & 36 & 7 \\
\hline \multirow[t]{3}{*}{ Glass et al. (29) } & EPA & 22 & 3.3 & 11 & 4 & 7 & 7 & 7 & 2.6 & 95 & 12 & NR & NR \\
\hline & $B M G$ & 5 & & & & & & & & 80 & & & \\
\hline & Flap & 2 & & & & & & & & 50 & & & \\
\hline \multirow[t]{3}{*}{ Meeks et al. (30) } & EPA & 24 & 1.75 & 15 & 7 & 6 & $N R$ & 9.3 & 2.9 & 73 & 5.1 & 50 & 3 \\
\hline & BMG & 2 & & & & & & & & & & & \\
\hline & Flap & 4 & & & & & & & & & & & \\
\hline Vetterlein et al. (33) & BMG & 47 & 3.6 & 33 & 5 & 8 & 1 & NR & NR & 67 & 3 & NR & NR \\
\hline
\end{tabular}

EPA, Excision and Primary Anastomosis; BMG, Buccal Mucosa Graft; FU, Follow-Up; EBRT, External Beam Radiotherapy; BT, Brachytherapy; NR, Not Reported. 


\section{Substitution Urethroplasty}

Even more than in the EPA technique, urethroplasty using grafts or flaps is impaired by the poor quality of the irradiated surrounding tissue. Substitution urethroplasty is used for longer strictures and when EPA is no longer feasible (Table 1).

In a retrospective cohort of Vetterlein et al. 47 patients underwent buccal mucosa ventral urethroplasty. Mean graft length was $5 \mathrm{~cm}$. A recurrence rate of $33 \%$ was observed. In this study validated questionaires (USS-PROM) were used to evaluate patient reported outcomes. Postoperatively 53\% patients reported daily urinary incontinence, and $26 \%$ required an artificial urinary sphincter implantation. Erectile dysfunction or absence of sexual activity was present in almost all of the patients (33).

In the case series of Hofer et al. 6 patients with a median strictyure length of $4.25 \mathrm{~cm}$ were treated with substitution urethroplasty. Only one patient had a recurrence at 5.5 years follow-up. New onset urinary incontinence was present in 50\% of the patients. There was no change in erectile function after surgery (28).

Palmer describes ventral onlay buccal mucosa urethroplasty and use of a gracilis muscle flap for long segment complex strictures. The gracilis muscle flap provides a well-vascularized graft bed for the buccal graft. Mean stricture length was $8.2 \mathrm{~cm}$ and in 9 of the 20 patients stricture etiology was radiotherapy. A patency rate of $80 \%$ was achieved at a mean follow-up of 40 months. Mean time to stricture recurrence was 10 months (36).

A multi-institutional retrospective series of dorsal onlay buccal mucosa urethroplasty in 79 patients, showed a patency rate of $82.3 \%$, and a de novo incontinence rate of $8 \%$. There was a short median follow-up of 21 months (32).

\section{Urinary Diversion}

When there are no more reconstructive options left and patients have a refractory bladder outlet obstruction or other severe symptoms such as uncontrollable pelvic pain, urinary diversion can be discussed.

In a case series of Sack et al. 15 patients with previous radiotherapy and/or cryotherapy were treated with surgical extirpation and urinary diversion for different radio- or cryotherapy induced problems including urethral strictures. There were on average 3.7 failed previous interventions. Surgical extirpation (cystectomy or cystoprostatectomy) was performed and urinary diversion was accomplished by ileal conduit, catheterizable pouch or colon conduit. Perioperative morbidity was higher than in a non-irradiated population. Postoperative quality of life (QoL) was measured, and patients reported a satisfying outcome and would have undergone the surgery sooner (37).

$\mathrm{Al}$ Hussein $\mathrm{Al}$ Awamlh et al. also reports a significant improve in QoL, despite perioperative complication risks, in patients with severe radiotherapy related complications (fistulas, radiation cystitis, pelvic pain or incontinence) (38).

In case of preserved bladder capacity bladder preservation can be attempted, with closure of the bladder neck and continent urinary diversion (20).

\section{DISCUSSION}

Radiotherapy induces oxidative stress, resulting in an effective cancer treatment as a short term result. However, on the long term it causes chronic inflammation and micro-angiopathy, resulting in tissue damage. This late side-effect explains the potential late onset of radiation-induced complications.

No studies so far were able to demonstrate a firm correlation between urethral strictures and urethral dose of radiation. However, more profound dosimetric studies should be performed to support this conclusion.

The management of radiation-induced urethral strictures is complicated due to several reasons: the proximity of the external urethral sphincter since most of these strictures are located in the bulbomembranous urethra, the poor quality of local tissue needed for reconstruction and impaired vascularity that will lead to a difficult wound healing process $(25,39)$.

Literature is still limited and most studies are small retrospective case series. As a result of this consideration as a late onset complication, a significant amount of studies has a high rate of loss to follow-up, possibly underestimating the prevalence.

Conservative management can be an option in frail patients, or when reconstructive surgery is no longer a viable option, and usually consists of chronic urinary drainage. Chronic catheter related problems should be taken into account.

Endoluminal treatment has a success rate between 0 and $51 \%$, based on retrospective case series $(4,13,22,23)$. A single endoluminal treatment can be attempted since it has an acceptable patency rate and a much lower incontinence rate than open reconstruction. On the contrary repetitive DVIU or dilatation might provoke further fibrosis of the radiated tissue and can lead to a delay of more reliable reconstructive options. Intermittent selfcatheterization can be used as a palliative treatment, when no other reconstructive options are left $(4,6$, $13,24)$. However, it is often associated with a lower quality of life (26).

Excision and primary anastomosis of radiation-induced strictures provides durable long term results, with patency rates up to $90 \%$. Most authors also emphasize the feasibility of this technique in most of the cases, provided the stricture is short enough to allow tension-free anastomosis.

For longer strictures, substitution urethroplasty must be performed. Although even more prone to the radiation induced reduction of tissue quality then EPA, long term success rates up to $84 \%$ are reported, in small case series. Since this technique is used less frequently then EPA, all studies consist of small case series, so results must be interpretated with caution.

When primary reconstructive techniques fail or concomitant severe symptoms are present, urinary diversion with or without extirpation should be discussed with the patient. Depending on the residual bladder function continent or incontinent diversions can be considered (20). These procedures have a higher complication rate in patients who underwent radiotherapy (37).

After endoluminal treatment a new onset urinary incontinence rate of $10 \%$ was reported $(4,13,22,23)$.

Deterioration or new onset of urinary incontinence after urethroplasty for radiation-induced strictures (EPA and 
substitution urethroplasty) is present in $11-50 \%$ of the patients. Incontinence can be mild but a minority of patients will need an artificial urinary sphincter. Incontinence rates are higher after urethroplasty for radiation-induced strictures in comparison to other etiology (35).

Most of the studies report mainly unaltered erectile function after the treatment of radiation-induced strictures $(28,30)$. This is probably due to the high rates of erectile dysfunction present prior to surgery as a result of the radiotherapy itself. The cavernous nerves located dorsally to the posterior urethra are preserved during some techniques of substitution urethroplasty in contrast to EPA, however this doesn't seem to influence the already low deterioration in erectile function postoperatively.

Concerning the complications a limitation in almost all of these studies was a lack of validated questionnaires to evaluate patient reported outcome measures.

Even when a radiation-induced stricture is successfully treated patients can experience persistent symptoms due to radiation toxicity, for example impaired bladder capacity due to radiocystitis.

\section{REFERENCES}

1. Awad MA, Gaither TW, Osterberg EC, Murphy GP, Baradaran N, Breyer BN. Prostate cancer radiation and urethral strictures: a systematic review and meta-analysis. Prostate Cancer Prostatic Dis. (2018) 21:168-74. doi: 10.1038/s41391-017-0028-3

2. Herschorn S, Elliott S, Coburn M, Wessells H, Zinman L. SIU/ICUD consultation on urethral strictures: posterior urethral stenosis after treatment of prostate cancer. Urology. (2014) 83 (3 Suppl.):S59-70. doi: 10.1016/j.urology.2013.08.036

3. Stone HB, Coleman CN, Anscher MS, McBride WH. Effects of radiation on normal tissue: consequences and mechanisms. Lancet Oncol. (2003) 4:529-36. doi: 10.1016/S1470-2045(03)01191-4

4. Sullivan L, Williams SG, Tai KH, Foroudi F, Cleeve L, Duchesne GM. Urethral stricture following high dose rate brachytherapy for prostate cancer. Radiother Oncol. (2009) 91:232-6. doi: 10.1016/j.radonc.2008.11.013

5. Hughes M, Caza T, Li G, Daugherty M, Blakley S, Nikolavsky D. Histologic characterization of the post-radiation urethral stenosis in men treated for prostate cancer. World J Urol. (2020) 38:2269-77. doi: 10.1007/s00345-019-03031-y

6. Browne BM, Vanni AJ. Management of urethral stricture and bladder neck contracture following primary and salvage treatment of prostate cancer. Curr Urol Rep. (2017) 18:76. doi: 10.1007/s11934-017-0729-0

7. Elliott SP, Meng MV, Elkin EP, McAninch JW, Duchane J, Carroll PR, et al. Incidence of urethral stricture after primary treatment for prostate cancer: data from CaPSURE. J Urol. (2007) 178:529-34. Discussion 34. doi: 10.1016/j.juro.2007.03.126

8. Heyns C, Van der Merwe J, Basson A, Van der Merwe, A. Etiology of male urethral strictures-evaluation of temporal changes at a single center, and review of the literature. Afr J Urol. (2012) 18:4-9. doi: 10.1016/j.afju.2012.04.009

9. Lumen N, Hoebeke P, Willemsen P, De Troyer B, Pieters R, Oosterlinck W. Etiology of urethral stricture disease in the 21st century. J Urol. (2009) 182:983-7. doi: 10.1016/j.juro.2009.05.023

10. Rodda S, Tyldesley S, Morris WJ, Keyes M, Halperin R, Pai H, et al. ASCENDE-RT: an analysis of treatment-related morbidity for a randomized trial comparing a low-dose-rate brachytherapy boost with a dose-escalated external beam boost for high- and intermediate-risk prostate cancer. Int J Radiat Oncol Biol Phys. (2017) 98:286-95. doi: 10.1016/j.ijrobp.2017.01.008

11. Earley JJ, Abdelbaky AM, Cunningham MJ, Chadwick E, Langley SE, Laing RW. Correlation between prostate brachytherapy-related urethral stricture

\section{CONCLUSION}

Management of radiation induced urethral strictures remains challenging, with an uncertain outcome and a significant amount of side-effects. Experienced operative skills with good knowledge of all the techniques are required to increase the chance of a good long-term outcome. Quality of life is important to take into account, especially since the prognosis of prostate cancer has been improved over the last decades.

Patients should be informed that returning to a urological situation prior to their prostate cancer treatment is not a realistic expectation, since radiation-induced bladder dysfunction can impair outcome of reconstructive surgery.

\section{AUTHOR CONTRIBUTIONS}

All authors listed have made a substantial, direct and intellectual contribution to the work, and approved it for publication.

and peri-apical urethral dosimetry: a matched case-control study. Radiother Oncol. (2012) 104:187-91. doi: 10.1016/j.radonc.2012.06.001

12. Martinez AA, Gonzalez J, Ye H, Ghilezan M, Shetty S, Kernen K, et al. Dose escalation improves cancer-related events at 10 years for intermediate- and high-risk prostate cancer patients treated with hypofractionated high-doserate boost and external beam radiotherapy. Int J Radiat Oncol Biol Phys. (2011) 79:363-70. doi: 10.1016/j.ijrobp.2009.10.035

13. Merrick GS, Butler WM, Wallner KE, Galbreath RW, Anderson RL, Allen $\mathrm{ZA}$, et al. Risk factors for the development of prostate brachytherapy related urethral strictures. J Urol. (2006) 175:1376-80. Discussion 81. doi: 10.1016/S0022-5347(05)00681-6

14. Hindson BR, Millar JL, Matheson B. Urethral strictures following high-doserate brachytherapy for prostate cancer: analysis of risk factors. Brachytherapy. (2013) 12:50-5. doi: 10.1016/j.brachy.2012.03.004

15. Mohammed N, Kestin L, Ghilezan M, Krauss D, Vicini F, Brabbins D, et al. Comparison of acute and late toxicities for three modern high-dose radiation treatment techniques for localized prostate cancer. Int J Radiat Oncol Biol Phys. (2012) 82:204-12. doi: 10.1016/j.ijrobp.2010.10.009

16. Deger S, Boehmer D, Roigas J, Schink T, Wernecke KD, Wiegel T, et al. High dose rate (HDR) brachytherapy with conformal radiation therapy for localized prostate cancer. Eur Urol. (2005) 47:441-8. doi: 10.1016/j.eururo.2004.11.014

17. Seymore $\mathrm{CH}$, el-Mahdi AM, Schellhammer PF. The effect of prior transurethral resection of the prostate on post radiation urethral strictures and bladder neck contractures. Int J Radiat Oncol Biol Phys. (1986) 12:1597-600. doi: 10.1016/0360-3016(86)90283-X

18. Merrick GS, Butler WM, Tollenaar BG, Galbreath RW, Lief JH. The dosimetry of prostate brachytherapy-induced urethral strictures. Int J Radiat Oncol Biol Phys. (2002) 52:461-8. doi: 10.1016/S0360-3016(01)01811-9

19. Harrison SC, Lawrence WT, Morley R, Pearce I, Taylor J. British Association of Urological Surgeons' suprapubic catheter practice guidelines. BJU Int. (2011) 107:77-85. doi: 10.1111/j.1464-410X.2010.09762.x

20. Anderson KM, Higuchi TT, Flynn BJ. Management of the devastated posterior urethra and bladder neck: refractory incontinence and stenosis. Transl Androl Urol. (2015) 4:60-5. doi: 10.3978/j.issn.2223-4683.2015.02.02

21. Fuchs JS, Sheth K, Viers BR, Hofer MD, Pagliara TJ, Scott JM, et al. Role of chronic suprapubic tube in the management of radiation induced urethral strictures. Urol Pract. (2017) 4:479-85. doi: 10.1016/j.urpr.2016.10.004

22. Brandes SB. Radiotherapy-Induced Urethral Strictures. New York, NY: Humana Press (2014). p. 337-50

23. Chen ML, Correa AF, Santucci RA. Urethral strictures and stenoses caused by prostate therapy. Rev Urol. (2016) 18:90-102. doi: 10.3909/riu0685 
24. Farrell MR, Sherer BA, Levine LA. visual internal urethrotomy with intralesional mitomycin $\mathrm{C}$ and short-term clean intermittent catheterization for the management of recurrent urethral strictures and bladder neck contractures. Urology. (2015) 85:1494-9. doi: 10.1016/j.urology.2015.02.050

25. Hofer MD, Liu JS, Morey AF. Treatment of radiation-induced urethral strictures. Urol Clin North Am. (2017) 44:87-92. doi: 10.1016/j.ucl.2016.08.005

26. Lubahn JD, Zhao LC, Scott JF, Hudak SJ, Chee J, Terlecki R, et al. Poor quality of life in patients with urethral stricture treated with intermittent self-dilation. J Urol. (2014) 191:143-7. doi: 10.1016/j.juro.2013. 06.054

27. Rourke K, Kinnaird A, Zorn J. Observations and outcomes of urethroplasty for bulbomembranous stenosis after radiation therapy for prostate cancer. World J Urol. (2016) 34:377-82. doi: 10.1007/s00345-015-1 608-2

28. Hofer MD, Zhao LC, Morey AF, Scott JF, Chang AJ, Brandes SB, et al. Outcomes after urethroplasty for radiotherapy induced bulbomembranous urethral stricture disease. J Urol. (2014) 191:1307-12. doi: 10.1016/j.juro.2013.10.147

29. Glass AS, McAninch JW, Zaid UB, Cinman NM, Breyer BN. Urethroplasty after radiation therapy for prostate cancer. Urology. (2012) 79:1402-5. doi: 10.1016/j.urology.2011.11.077

30. Meeks JJ, Brandes SB, Morey AF, Thom M, Mehdiratta N, Valadez $\mathrm{C}$, et al. Urethroplasty for radiotherapy induced bulbomembranous strictures: a multi-institutional experience. J Urol. (2011) 185:1761-5. doi: 10.1016/j.juro.2010.12.038

31. Fuchs JS, Hofer MD, Sheth KR, Cordon BH, Scott JM, Morey AF. Improving outcomes of bulbomembranous urethroplasty for radiationinduced urethral strictures in post-urolume era. Urology. (2017) 99:240-5. doi: 10.1016/j.urology.2016.07.031

32. Policastro CG, Simhan J, Martins FE, Lumen N, Venkatesan K, Angulo JC, et al. A multi-institutional critical assessment of dorsal onlay urethroplasty for post-radiation urethral stenosis. World J Urol. (2020). doi: 10.1007/s00345-020-03446-y. [Epub ahead of print].

33. Vetterlein MW, Kluth LA, Zumstein V, Meyer CP, Ludwig TA, Soave A, et al. Buccal mucosal graft urethroplasty for radiation-induced urethral strictures: an evaluation using the extended urethral stricture surgery patientreported outcome measure (USS PROM). World J Urol. (2020) 38:2863-72. doi: 10.1007/s00345-020-03102-5

34. Elliott SP, McAninch JW, Chi T, Doyle SM, Master VA. Management of severe urethral complications of prostate cancer therapy. J Urol. (2006) 176 (6 Pt 1):2508-13. doi: 10.1016/j.juro.2006.07.152

35. Chung PH, Esposito P, Wessells H, Voelzke BB. Incidence of stress urinary incontinence after posterior urethroplasty for radiation-induced urethral strictures. Urology. (2018) 114:188-92. doi: 10.1016/j.urology.2017.11.024

36. Palmer DA, Buckley JC, Zinman LN, Vanni AJ. Urethroplasty for high risk, long segment urethral strictures with ventral buccal mucosa graft and gracilis muscle flap. J Urol. (2015) 193:902-5. doi: 10.1016/j.juro.2014.09.093

37. Sack BS, Langenstroer P, Guralnick ML, Jacobsohn KM, O'Connor RC. Cystectomy and urinary diversion for the management of a devastated lower urinary tract following prostatic cryotherapy and/or radiotherapy. WMJ. (2016) 115:70-3.

38. Al Hussein Al Awamlh B, Lee DJ, Nguyen DP, Green DA, Shariat SF, Scherr DS. Assessment of the quality-of-life and functional outcomes in patients undergoing cystectomy and urinary diversion for the management of radiation-induced refractory benign disease. Urology. (2015) 85:394-400. doi: 10.1016/j.urology.2014.08.047

39. Lumen N, Oosterlinck W. Challenging non-traumatic posterior urethral strictures treated with urethroplasty: a preliminary report. Int Braz J Urol. (2009) 35:442-9. doi: 10.1590/S1677-55382009000400008

Conflict of Interest: The authors declare that the research was conducted in the absence of any commercial or financial relationships that could be construed as a potential conflict of interest.

Copyright (c) 2021 Waterloos, Martins, Verla, Kluth and Lumen. This is an openaccess article distributed under the terms of the Creative Commons Attribution License (CC BY). The use, distribution or reproduction in other forums is permitted, provided the original author(s) and the copyright owner(s) are credited and that the original publication in this journal is cited, in accordance with accepted academic practice. No use, distribution or reproduction is permitted which does not comply with these terms. 